\title{
Dihydropyrimidine Dehydrogenase Activity and Thymidylate Synthase Level Are Associated with Response to 5-fluorouracil in Human Colorectal Cancer
}

\author{
YASUMI ARAKI, HIROHARU ISOMOTO* AND KAZUO SHIROUZU \\ Department of Surgery, Kurume University School of Medicine, Kurume 830-0011 and \\ *Department of Surgery, Kurume University Medical Center, Kurume 839-0863, Japan
}

\begin{abstract}
Summary: In the recent studies associated with the modulation of 5-fluorouracil (5-FU) and the development of new antifolates, attentions have been focused on the expression of the target enzymes, thymidylate synthase (TS) and dihydropyrimidine dehydrogenase (DPD), that affect tumor sensitivity and resistance to drugs. In order to evaluate predictability of therapeutic efficacy by intratumoral enzyme activity, we investigated the role of TS content and DPD activity in tumor sensitivity to 5 -FU. Surgical specimens were obtained from 51 patients with colorectal cancer and used to measure TS content and DPD activity. TS content and DPD activity in tissues were measured by $\left[{ }^{3} \mathrm{H}\right]$-FdUMP binding assay and radioenzymatic assay, respectively. The sensitivity to 5 -FU in tumor specimens was determined by collagen-gel droplet embedded-drug sensitivity test (CDDST). The TS content and DPD activity did not correlate with Dukes' staging. There was no correlation between TS content and DPD activity in any tumors. Simple linear regression analysis showed that neither DPD activity $(r=-0.267, p>0.05)$ nor TS content $(r=-0.277, p>0.05)$ in tumors had a significant correlation with 5-FU effectiveness independently. Four out of 24 patients, highly responsive to 5-FU, showed low levels in both DPD and TS. The patients with high value in either DPD activity or TS content proved not to respond to 5-FU. In conclusion, these results demonstrate that both tumor DPD activity and TS content are the factors predicting 5-FU responsiveness in colorectal cancer.
\end{abstract}

Key words thymidylate synthase, dihydropyrimidine dehydrogenase, 5-FU sensitivity, colorectal cancer

\section{INTRODUCTION}

For the past forty years, 5-FU [1] has remained the agent of choice in the treatment of patients with advanced colorectal cancer. However, the response rates are generally less than $20 \%$ and a number of combination therapies have been investigated to improve the effectiveness of 5-FU [2]. There is thus a potential interest in early identification of individual tumor response to 5-FU.

Intracellular activation of 5-FU involves several enzyme pathways leading to at least three well-identified cellular targets, i.e., TS inhibition, production of F-RNA, and misincorporation of FdUTP into DNA, but it has been mainly displayed by inhibition of TS, a rate-limiting enzyme in de novo DNA biosynthesis, and by 5-fluoro-2'-deoxyuridylate (FdUMP), an active metabolite of 5-FU, forming an inactive ternary complex with 5, 10-methylenetetrahydrofolate [3-7].

Consequently, Spears et al. [8,9] have suggested that the response to 5-FU is influenced by the activity of TS in the tumor as well as by other factors such as an intracellular endogenous nucleotide, 2'deoxyuridylate (dUMP), and reduced folates. More recently, several reports have demonstrated the significance of the TS expression level as one of prognostic factors of cancer patients after surgery [1016]. Meanwhile, DPD is the first and rate-limiting 
enzyme of a chain of reactions which regulate 5-FU catabolism [17]. The underlying differences of DPD activity in tumors induce the difference in FU degradation prior to 5-FU engagement in the anabolic pathway. Some authors have thus shown that intratumoral DPD activity or mRNA expression level is one of the good predictors for clinical outcome after 5FU-based chemotherapy [18-20]. From these finding, both TS level and DPD activity in tumors may be potential factors controlling the sensitivity to 5-FU.

In this report, we describe the correlation between the TS level or DPD activity in tumors and their sensitivity to 5-FU in vitro in human colorectal cancer.

\section{PATIENTS AND METHODS}

\section{Patients}

Evaluation of DPD and TS level was conducted in 51 consecutive patients undergoing surgery for colorectal cancer. This study was approved by the local ethical committee, and written informed consent was obtained from all patients. Immediately after resection, portions of various tumors and adjacent normal tissues (10 cm from the tumor) were removed by an experienced gastrointestinal pathologist and frozen in liquid nitrogen.

\section{Chemicals}

5-FU was purchased from Wako Pure Chemical Industries, Osaka, Japan; $\left[6-{ }^{14} \mathrm{C}\right] 5-\mathrm{FU}(56 \mathrm{mCi} / \mathrm{mmol})$ was from American Radiolabeled Chemicals, Inc., MO, USA, and all other chemicals used were of commercially available products of the highest quality.

\section{Analysis of DPD activity}

Enzyme solution was prepared as described by Naguib et al. [17]. Frozen tissues were weighed and homogenized in the buffer A $(20 \mathrm{mM}$ potassium phosphate, $\mathrm{pH} 8.0$, and $1 \mathrm{mM}$ mercaptoethanol). The homogenate was centrifuged at $100,000 \mathrm{~g}$ for $60 \mathrm{~min}$ at $4{ }^{\circ} \mathrm{C}$. The cytosolic fraction was retained for use in DPD activity assay. The protein level in cytosol was determined by the Bradford assay (Bio-Rad, Munich, Germany). In brief, a reaction mixture consisting of $250 \mu \mathrm{M}\left[{ }^{14} \mathrm{C}\right] 5-\mathrm{FU}$, buffer $\mathrm{A}$ and cytosol in a final volume of $125 \mu \mathrm{l}$ was incubated for $45 \mathrm{~min}$ at $37{ }^{\circ} \mathrm{C}$ in a shaking water bath. DPD activity was determined by measuring the sum of the products, dihydrofluouracil (DHFU), 2-fluoro- $\beta$-ureidopropionate (F- $\beta$-UPA), and F- $\beta$-Ala, formed from $\left[6-{ }^{14} \mathrm{C}\right] 5$-FU, as described by Naguib et al. [17,21]. The mixture after the reaction was added to $25 \mu \mathrm{l}$ of $0.36 \mathrm{mM}$ $\mathrm{KOH}$, allowed to stand at room temperature for at least $30 \mathrm{~min}$ to hydrolyze the DHFU formed, mixed with $25 \mu \mathrm{l}$ of $0.36 \mathrm{mM} \mathrm{HCLO}_{4}$ for neutralization and centrifuged (14,000 rpm, $5 \mathrm{~min})$. A $5 \mu \mathrm{l}$ aliquot of the supernatant was applied to a TLC plate (silica gel 60 F254, Merck, Germany), and developed with a mixture of ethanol and $1 \mathrm{M}$ ammonium acetate (5:1, $\mathrm{v} / \mathrm{v})$. Each product was visualized and quantified using an imaging analyzer (BAS-2000, Fujix, Tokyo, Japan). The $\mathrm{Rf}$ values for 5 -FU, DHFU, and F- $\beta$ UPA and F- $\beta$-Ala were $0.79,0.58$, and 0.34 , respectively.

\section{TS level}

TS level was measured as described by Spears et al. [8-10]. Three volumes of $0.2 \mathrm{M}$ tris-HCL buffer, $\mathrm{pH} 7.4$, cooled to $4{ }^{\circ} \mathrm{C}$ and containing $20 \mathrm{mM}$ 2-mercaptoethanol, $15 \mathrm{mM}$ cytidylate, and $100 \mathrm{mM} \mathrm{NaF}$ were added to the tumor tissue. The tissue was then cut into pieces with scissors, homogenized and sonicated. Cytosol was prepared by centrifugation at $105,000 \times \mathrm{g}$ for $60 \mathrm{~min}$ and used for the TS assay. To measure free TS, $50 \mu \mathrm{l}$ of buffer A $(600 \mathrm{mM}$ $\mathrm{NH}_{4} \mathrm{HCO}_{3}, 100 \mathrm{mM}$-2-mercaptoethanol, $100 \mathrm{mM}$ $\mathrm{NaF}$ and $15 \mathrm{mM}$ cytidylate, $\mathrm{pH} 8.0$ ) and $50 \mu \mathrm{l}$ of cyosol were added to the mixture to be incubated for 20 min. Incubation was done at $30{ }^{\circ} \mathrm{C}$ with $7.8 \mathrm{pmol}$ of [6- $\left.{ }^{3} \mathrm{H}\right]$ FdUMP enzymatically synthesized from [6$\left.{ }^{3} \mathrm{H}\right] 5-\mathrm{FU}$ (New England Nuclear, USA) in $50 \mu \mathrm{l}$ of 5 $\mathrm{mM}$ potassium phosphate buffer, $\mathrm{pH} 7.4$, plus $25 \mu \mathrm{l}$ of a cofactor solution $(50 \mathrm{mM}$ potassium phosphate buffer, $\mathrm{pH}$ 7.4, containing $20 \mathrm{mM}$ 2-mercaptoethanol, $100 \mathrm{mM} \mathrm{NaF}, 15 \mathrm{mM}$ cytidylate, $2 \%$ bovine serum albumin, $2 \mathrm{mM}$ tetrahydrofolic acid, $16 \mathrm{mM}$ sodium ascorbate, and $9 \mathrm{mM}$ formaldehyde). Total TS was assayed by preincubating buffer A with cytosol for 3 hrs at $26{ }^{\circ} \mathrm{C}$. Incubated mixtures in triplicate were centrifuged at $2.000 \times \mathrm{g}$ for $15 \mathrm{~min}$ after the addition of cold $\left(4{ }^{\circ} \mathrm{C}\right) 10 \mathrm{~N}$ perchloric acid to remove unbound FdUMP. Each precipitate was washed 3 times with $0.5 \mathrm{~N}$ perchloric acid. The final precipitates were dissolved in $0.5 \mathrm{ml}$ of formic acid and ACS-11 scintillator (Amersham, Buckinghamshire, UK). The radioactivity level was also measured.

\section{$C D-D S T$}

The fresh specimens used in this study were obtained from 24 patients with a diagnosis of colorectal cancer. The specimens were freshly resected and each weighed at least $0.3 \mathrm{~g}$. Each fresh surgical specimen was minced finely using a scalpel and sus- 
pended in $0.1 \%$ Hanks' balanced saline solution (EZ) (Nitta Gelatin, Japan) at $37{ }^{\circ} \mathrm{C}$ for $3 \mathrm{hrs}$. After digestion, each sample was centrifuged at $900 \mathrm{~g}$ for $3 \mathrm{~min}$ and filtered through a $80-\mu \mathrm{m}$-pore nylon mesh. The recovered cells were washed in HBSS and suspended in PCM-1 medium (Nitta Gelatin) in a $\mathrm{CO}_{2}$ incubator at $37{ }^{\circ} \mathrm{C}$ for $24 \mathrm{hrs}$. Collagen was then dissolved using a cell dispersion enzyme, and only the viable cells were collected by centrifugation. The collected viable cells were dispersed at a density of $1 \times 10^{5}$ cells $/ \mathrm{ml}$ in collagen solution, which was a mixture of type I collagen (Nitta Gelatin), 10× F-12 medium and reconstitution buffer at a ratio of $8: 1: 1$. Three droplets of the collagen-cell mixture were placed in the wall of a six-well multiplate on ice, and allowed to gel in a $\mathrm{CO}_{2}$ incubator at $37{ }^{\circ} \mathrm{C}$ for $1 \mathrm{hr}$. The final concentration was about $3 \times 10^{3}$ cells per collagen gel droplet. Three milliliter of DF medium (Nissui, Tokyo, Japan), containing $10 \%$ fetal bovine serum (Gibco, NY, USA) was overlaid, and then incubated in a $\mathrm{CO}_{2}$ incubator at $37{ }^{\circ} \mathrm{C}$ overnight. 5-FU was added at final concentrations of $1.0 \mu \mathrm{g} / \mathrm{ml}$ and incubated for $24 \mathrm{hrs}$. After removal of the medium containing the anticancer drugs, each sample was washed with HBSS, overlaid with $4 \mathrm{ml}$ serum-free media (PCM-2; Nitta Gelatin), and incubated for 7 days at $37{ }^{\circ} \mathrm{C}$ with replacement of the media on the fourth day of incubation. After 7 days of incubation, neutral red (Nitta Gelatin) was added to each well at a final concentration of $50 \mu \mathrm{g} / \mathrm{ml}$, and the colonies in the collagen gel droplets were stained for 2 hrs. Each colony was fixed in $10 \%$ neutral formalin buffer, washed with water and dried in air. Quantification of the total volume of the tumor colonies, utilizing differences in the growth morphologies between tumor cells and fibroblasts, was conducted by an image analysis method described previously [22-26]. Evaluation of the anticancer drug effects was based on the ratio of the total volume of tumor colonies in the drug treated group (T) to that of the colonies in the untreated group (C). After culture for 7 days, the anticancer drugs was considered effective when $\mathrm{T} / \mathrm{C} \%$ was less than or equal to $50 \%$, borderline when it was greater than $50 \%$ and less than or equal to $60 \%$, and not effective when it was greater than $60 \%$.

\section{Statistical analysis}

As TS and DPD levels exhibited asymmetrical distributions, nonparametric tests were applied for statistical analysis. The Wilcoxon paired test was performed for intrapatient analysis of TS and DPD activity in tumoral and nontumoral tissues. The level of statistical significance was $\mathrm{p}<0.05$.

\section{RESULTS}

Table 1 shows the relationships between histopathological findings and the enzyme activities for the primary colorectal cancer. The enzyme activities were assessed in 51 consecutive patients (32 males, 19 females) with colorectal cancer. The tumors were located in the colon (29/51) or rectum (22/51).

TABLE 1.

Clinical characteristics of 51 patients with colorectal cancer and enzyme activities for the colorectal cancer

\begin{tabular}{|c|c|c|c|c|c|}
\hline Variable & $\begin{array}{l}\text { No. of } \\
\text { patients }\end{array}$ & $\begin{array}{c}\mathrm{DPD} \\
(\mathrm{pmol} / \mathrm{mg} / \mathrm{min})\end{array}$ & $P$ value & $\begin{array}{c}\mathrm{TS} \\
(\mathrm{pmol} / \mathrm{g})\end{array}$ & $P$ value \\
\hline \multicolumn{6}{|l|}{ Sex } \\
\hline Male & 32 & $103.9 \pm 111.4$ & \multirow[t]{2}{*}{$\mathrm{p}<0.05$} & $5.0 \pm 2.7$ & \multirow[t]{2}{*}{ NS } \\
\hline Female & 19 & $49.5 \pm 32.8$ & & $4.7 \pm 3.1$ & \\
\hline \multicolumn{6}{|c|}{ Age (years) } \\
\hline$<65$ & 28 & $99.6 \pm 116.3$ & \multirow[t]{2}{*}{ NS } & $5.2 \pm 3.0$ & \multirow[t]{2}{*}{ NS } \\
\hline $65 \geqq$ & 23 & $64.2 \pm 51.4$ & & $4.5 \pm 2.7$ & \\
\hline \multicolumn{6}{|l|}{ Site } \\
\hline Colon & 29 & $91.6 \pm 116.5$ & \multirow[t]{2}{*}{ NS } & $4.5 \pm 2.8$ & \multirow[t]{2}{*}{ NS } \\
\hline Rectum & 22 & $73.1 \pm 51.3$ & & $2.9 \pm 8.5$ & \\
\hline \multicolumn{6}{|c|}{$\begin{array}{l}\text { Dukes' } \\
\text { classification }\end{array}$} \\
\hline A & 6 & $115.6 \pm 47.4$ & \multirow{4}{*}{ NS } & $5.0 \pm 2.1$ & \multirow{4}{*}{ NS } \\
\hline B & 16 & $85.4 \pm 46.6$ & & $5.2 \pm 3.0$ & \\
\hline \multirow[t]{2}{*}{$\mathrm{C}$} & 26 & $78.4 \pm 122.1$ & & $3.0 \pm 8.9$ & \\
\hline & 3 & $55.9 \pm 82.5$ & & $6.6 \pm 2.2$ & \\
\hline
\end{tabular}

Note: All data are means \pm SD. 


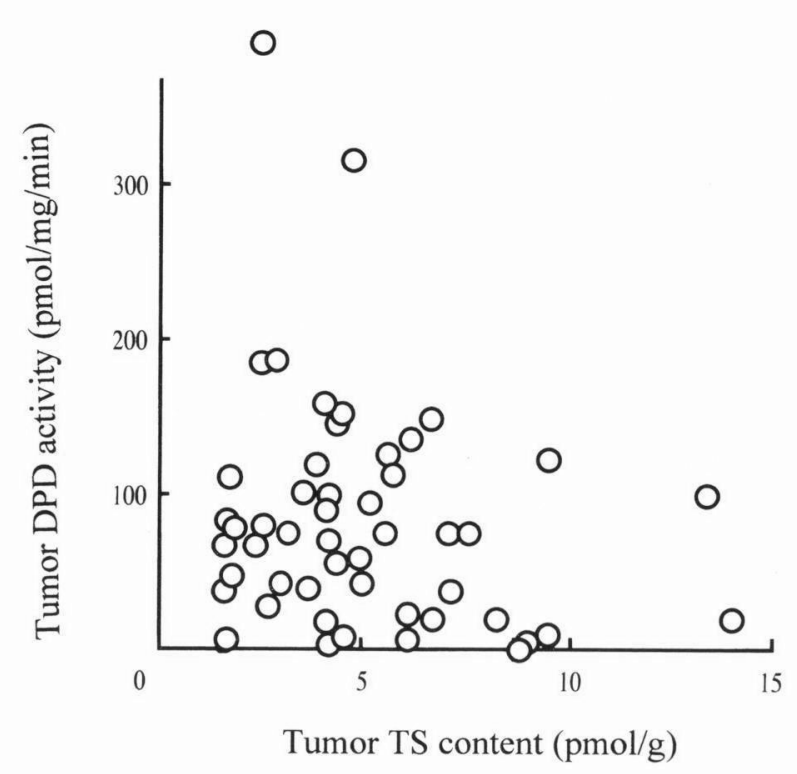

Fig. 1. Correlation between TS content and DPD activity in colorectal tumor.

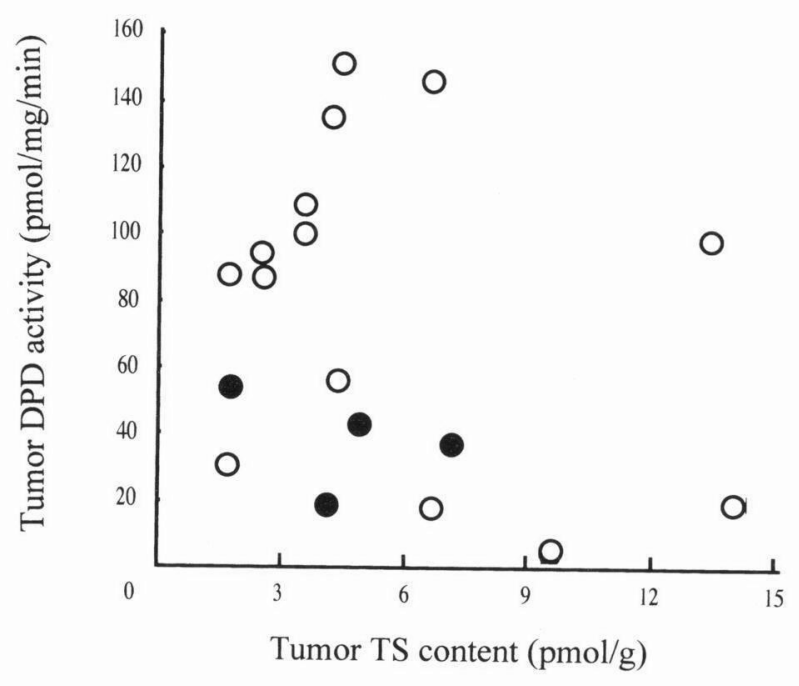

Fig. 3. Plotting DPD activity versus TS content. Open squares indicate $\mathrm{T} / \mathrm{C} \leqq 50 \%$, and closed squares indicate $\mathrm{T} / \mathrm{C}>50 \%$.

They were primarily at Duke's stage A (6/51), B (16/51), C (26/51) or D (3/51). TS content and DPD activity did not correlate with age, tumor location or Duke's stage, but DPD activity was higher in men (median $103.97 \mathrm{pmol} \mathrm{min} / \mathrm{mg}$ ) than in women (median $49.5 \mathrm{pmol} \mathrm{min} / \mathrm{mg})(\mathrm{p}<0.05)$.

There was no correlation between TS content and DPD activity in the tumors (Fig. 1). Simple linear regression analysis showed that neither DPD activity $(r=-0.267, p>0.05)$ nor TS content $(r=-0.277$,
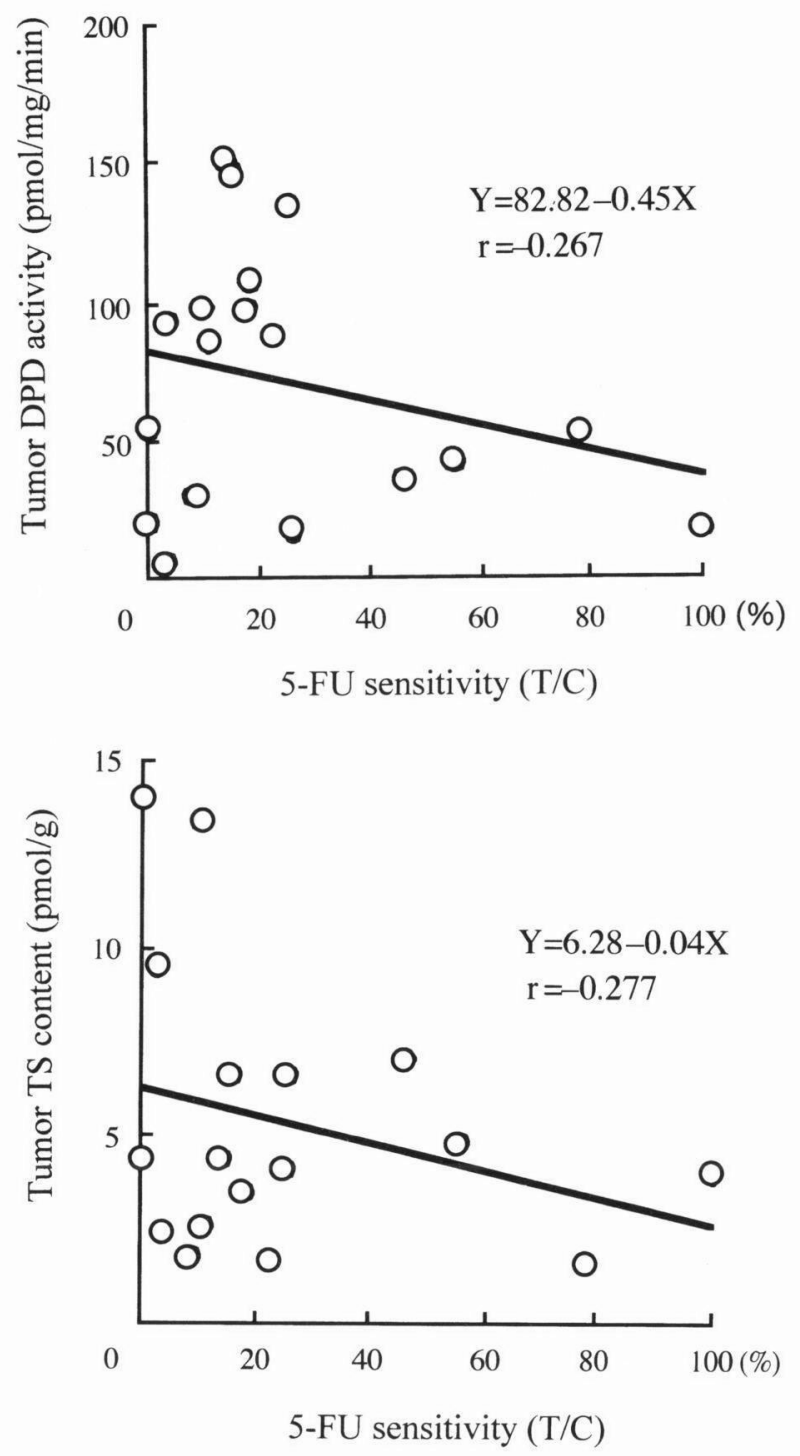

Fig. 2. Correlation between 5-FU sensitivity and TS content or DPD activity.

$\mathrm{p}>0.05)$ had a significant correlation with 5-FU effectiveness independently (Fig. 2). The four patients $(16.7 \%$; 4/24) who were highly responsive to $5-\mathrm{FU}$ showed low levels in both DPD and TS (Fig. 3)

\section{DISCUSSION}

This study is an interesting analysis to predict the sensitivity of colorectal cancer to 5-FU chemotherapy using TS level and DPD activity. The CD-DST in vitro chemosensitivity using three-dimensional culture is suitable for primary culturing, which is difficult to conduct by monolayer culture. This method can be performed with a small number of cells, is free of the fibroblast effects, and has been reported to 
be clinically useful in evaluating the chemosensitivity of various types of fresh surgical cancer specimens [24-26]. The CD-DST method has already been reported to be useful in reproducting the in vivo phenomena, since cells in vitro show similar sensitivity to the clinically reported results [24]. The CDDST method overcomes technical and theoretical limitations of the conventional chemosensitivity testing. Since in vitro sensitivity to various anticancer drugs was similar to the clinical response rate and predictable in a high proportion of patients (91\%), the CD-DST method may be clinically useful.

TS is an enzyme catalyzing the transformation from deoxyuridine to deoxythymidine, which is a rate-limiting stage in de novo thymidine nucleotide synthesis, and known to be a target enzyme for cytotoxity of 5-FU. 5-FU is metabolized in cells and transformed to fluorodeoxyuridine monophosphate (FdUMP). It is firmly bound to the foliate-binding site of TS, inhibits the enzyme activity, and consequently inhibits DNA synthesis [7,10,11].

On the other hand, DPD is the rate-limiting enzyme for 5-FU catabolism [17]. The increased DPD activity in colorectal cancer tissues tends to be associated with low sensitivity to 5-FU. Rapid enzymatic degradation from 5 -FU to $\mathrm{F}$ - $\beta$-alanine seems to inhibit the activation route by phosphoration and consequently decreases the sensitivity. Many investigators have reported that the levels of these enzymes influence the effectiveness of 5-FU. For example, high intratumoral TS mRNA and protein expression level is reportedly associated with resistance to 5-FU or poor prognosis in patients with gastric, colorectal or breast cancer [10-16]. In addition, basic experiments and clinical trials in colorectal, gastric, or head and neck cancer showed that patients with low intratumoral DPD mRNA expression level or activity were sensitive to 5-FU [18-20,27].

These enzymes have been reported to be expressed independently of each other [19,27], and our results also showed that intratumoral TS level did not correlate with DPD activity. We thus consider it quite likely that the sensitivity to 5-FU is regulated by the combination of the two enzymes, not by TS or DPD alone. In fact, there have been reports that the sensitivity to 5-FU is not correlated with DPD or TS $[18,20,27,28]$, which is presumably attributable to the possible regulation of the sensitivity by these enzymes combined. Our study also indicated that neither DPD nor TS was independently correlated with the sensitivity to 5-FU, but that the patients who had low activities in both the enzymes were highly sensitive to 5-FU. In the experiment using human tumor cell lines, Beck et al. have also shown that the cell lines which are low in both TS and DPD levels are more sensitive to 5-FU than those which have a high level in either of them [27].

Salonga et al. have also reported that low intratumoral DPD gene expression is associated with tumor response to 5-FU-based chemotherapy in colorectal cancer patients, but that low gene expression of all the three, TS, DPD and thymidine phosphorylase, in tumor can identify the responding patient more precisely [19].

Our results provide some interesting suggestion. The quantification of TS level and DPD activity is useful in identifying 5-FU-responsive patients and selecting appropriate drugs. For example, CPT-11 is effective in patients who have high TS level and low DPD activity. Saltz et al. have reported that patients with high TS mRNA expression level are also high intopoisomerase $1 \mathrm{mRNA}$ expression, and that such patients respond to CPT-11 [29]. On the other hand, patients who are low in TS level and high in DPD activity may benefit from TS inhibitions not metabolized by DPD such as raltitrexed [30] or the modulation of 5-FU with DPD inhibitions like eniluracil $[31,32]$. Seventeen percent of patients judged as responsive by CD-DST showed low levels in both DPD and TS, and this in vitro sensitivity rate coincided with the response rate of colorectal cancer to 5FU in general clinical setting. Meanwhile, 5-FUresistant tumors proved to be high in TS or DPD activity, or in both of them.

We conclude that DPD activity and TS level are promising and independent markers of sensitivity to $5 \mathrm{FU}$ in human colorectal cancer. The present data will encourage the coupled measurement of DPD and TS in tumor patients before 5-FU treatment in order to establish their prognostic relevance.

\section{REFERENCES}

1. Heiderberger C, Chaudhuri NK, and Duschinsky R. Fluorinated pyrimidines: a new class of tumor-inhibitory compounds. Nature 1957; 179:663-666.

2. Johnson PWM, Thompson PI, Seymour MT, Deasy NP, Thuraisingham $\mathrm{RC}$ et al. A less toxic regimen of 5fluorouracil and high-dose folinic acid for advanced gastrointestinal adenocarcinomas. Br J Cancer 1991; 64:603-605

3. Diasio RB, and Harris BE. Clinical pharmacology of 5fluorouracil. Clin Pharmacokin 1989; 16:215-237.

4. Parker WB, and Cheng YC. Metabolism and mechanism of action of 5-fluouracil. Pharm Ther 1990; 48:381-395. 
5. Danenberg PV. Thymidylate synthetase a target enzyme in cancer chemo-therapy. Biochem Biophys Acta 1977; 473:73-92.

6. Hartman KY, and Heidelberger C. Studies on fluorinated pyrimidines, VIII. Inhibition of thymidylate synthase. J Biol Chem 1961; 236:3006-3018.

7. Langenback RJ, Darnenberg PV, and Heidelberger C. Thymidylate synthase: mechanism of inhibition by 5fluoro-2'-deoxyuridylate. Biochem Biophys Res Commun 1972; 48:1565-1571.

8. Spears CD, Shahinian AH, Moran RG, Heidelberger C, and Corbett $\mathrm{TH}$. In vivo kinetics of thymidylate synthetase inhibition in 5-fluorouracil-sensitive and resistant murine colon adenocarcinomas. Cancer Res 1982; 43:450-456.

9. Spears CD, Gustavsson BG, Berne M, Frosing R, Bernstein $L$ et al. Mechanism of innate resistance to thymidylate synthase inhibition after 5-fluorouracil. Cancer Res 1988; 48:5894-5900.

10. Johnston PG, Fisher ER, Rockette HE, Fisher B, Wolmark $\mathrm{N}$ et al. The role of thymidylate synthase expression in prognosis and outcome of adjuvant chemotherapy in patients with rectal cancer. J Clin Oncol 1994; 12:2640-2647.

11. Peters GJ, van der Wolt CL, Groeningen CJ, Smid K, Meijer $\mathrm{S}$ et al. Thymidylate synthase inhibition after administration of fluorouracil with or without leucovorin in colon cancer patients: complications for treatment with fluorouracil. J Clin Oncol 1994; 12:2035-2042.

12. Johnston PG, Lenz HJ, Leichman CG, Danenberg KD, Allegra CJ et al. Thymidylate synthase gene and protein expression correlate and are associated with response to 5-fluorouracil in human colorectal and gastric tumors. Cancer Res 1995; 55:1407-1412.

13. Lenz HJ, Leichman CG, Danenberg KD, Danenberg PV, Groshen $\mathrm{S}$ et al. Thymidylate synthase mRNA level in adenocarcinoma of the stomach: a predictor for primary tumor response and overall survival. J Clin Oncol 1996; 4:176-182.

14. Pestalozzi BC, Peterson HF, Gelber RD, Goldhirsh A, Gusterson BA et al. Prognostic importance of thymidylate synthase expression in early breast cancer. J Clin Oncol 1997; 15:1923-1931.

15. Leichma CG, Lenz HJ, Leichman L, Danenberg K, Baranda $\mathrm{J}$ et al. Quantitation of intratumoral thymidylate synthase expression predicts for disseminated colorectal cancer response and resistance to protracted-infusion fluorouracil and weekly leucovorin. J Clin Oncol 1997; 15:3223-3229.

16. Aschele C, Debernardis D, Casazza S, Antonelli G, Tunesi $\mathrm{C}$ et al. Immunohistochemical quantitation of thymidylate synthase expression in colorectal cancer metastasis predicts for clinical outcome of fluorouracilbased chemotherapy. J Clin Oncol 1990; 17:1760-1770.

17. Naguib FMN, Kouni MH, and Cha S. Enzymes of uracil catabolism in normal and neoplastic human tissues. Cancer Res 1985; 45:5405-5412.

18. Ishikawa $Y$, Kubota T, Otani Y, Watanabe M, Teramoto $\mathrm{T}$ et al. Dihydropyrimidine dehydrogenase and messenger RNA levels in gastric cancer: possible predictor for sensitivity to 5-fluorouracil. Jpn J Cancer Res 2000; 91:105-112.

19. Salonga $\mathrm{D}$, Danenberg $\mathrm{KD}$, Johnson $\mathrm{M}$, Metzger $\mathrm{R}$, Groshen $\mathrm{S}$ et al. Colorectal tumors responding to 5fluouracil have low gene expression levels of dihydropyrimidine dehydrogenase, thymidylate synthase, and thymidine phosphorylase. Clin Cancer Res 2000; 6:13221327.

20. Etinne MC, Cheradame S, Fischel JL, Formento P, Dassonville $\mathrm{O}$ et al. Response to fluorouracil therapy in cancer patients: The role of tumoral dihydropyrimidine dehydrogenase activity. J Clin Oncol 1995; 13:1633-1670.

21. McMurrough J, and McLeod HL. Analysis of the dihydropyrimidine dehydrogenase polymorphism in a British population. Br J Clin Pharmacol 1996; 41:425-427.

22. Koezuka M, Kondo N, Kobayashi H, Hara S, and Yasutomi M. Drug sensitivity test for primary culture of human cancer cells using collagen gel embedded culture and image analysis. Int J Oncol 1993; 2:953-959.

23. Kobayashi H, Tanisaka K, Kondo N, Mito $\mathrm{Y}$, and Koezuka M. Development of new in vitro chemosensitivity test using collagen-gel droplet embedded culture and its clinical usefulness. Jpn J Cancer Chemothe 1995; 22:1933-1939.

24. Lawler EM, Miller FR, and Heppner GH. Significance of three-dimensional growth patterns of mammary tissues in collagen gels. In Vitro 1983; 19:600-610.

25. Yang $\mathbf{J}$, and Nandi S. Growth of cultured cells using collagen as substrate. Int Rev Cytol 1983; 81:249-286.

26. Araki Y, Isomoto H, Matsumoto A, Kaibara A, Yasunaga $\mathrm{M}$ et al. An in vitro chemosensitivity test for colorectal cancer using collagen-gel droplet embedded cultures. Kurume Med J 1999; 46:163-166.

27. Beck A, Etienne MC, Cheradame S, Fischel JL, Formento $\mathrm{P}$ et al. A role for dihydropyrimidine dehydrogenase and thymidylate synthase in tumour sensitivity to fluorouracil. Eur J Cancer 1994; 30:1517-1522.

28. Germ J, Danenberg K, Behan K, Parr A, Young L et al. Thymidine kinase, thymidylate synthase, dihydropyrimidine dehydrogenase $\&$ p53 profiles of cell lines in the National Cancer Institute anticancer drug screen. Am Asso Cancer Res 1999; 40:8.

29. Saltz L, Danenberg K, Paty P, Kelsen D, Kemeny N et al. High thymidylate synthase expression does not preclude activity of CPT-11 in colorectal cancer. Proc Am Soc Clin Oncol 1998; 17:28.

30. Young A, Topham C, and Moore J. A patient preference study comparing raltitrexed (Tomudex) and bolus or infusional 5-fluorouracil regimens in advanced colorectal cancer: influence of side effects and administration attributes. Eur J Cancer Care 1999; 8:154-161.

31. Baker SD, Diasio RB, O’Reilly S, Lucas VS, Khor SP et al. Phase I and pharmacologic study of oral fluouracil on a chronic daily schedule in combination with the dihydropyrimidine dehydrogenase inactivator eniluracil. J Clin Oncol 2000; 18:915-926.

32. Ahmed FY, Johnston SJ, Cassidy J, O’Kelly T, Binnie N et al. Eniluracil treatment completely inactivates dihydropyrimidine dehydrogenase in colorectal tumors. J Clin Oncol 1999; 17:2439-2445. 